\begin{tabular}{|l|l|}
\hline MS-6 & 649 \\
\hline
\end{tabular}

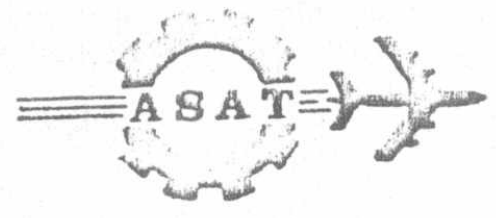

MILITARY TECHNICAL COLLEGE

CAIRO - EGYPT

FATIGUE CRACK CLOSURE IN ALUMINIUM ALLOYS

UNDER VARIABLE-AMPLITUDE LOADS

M.GABRA * and M.ABD-EL SALAM **

ABSTRACT

During fatigue crack propagation, resiaual aeformations are built up in front of the crack tip and left behind the propagating crack. As a result of these residual deformations the crack will close(at least partly) during unloading. At zero load the presence of these deformations excersises residual compressive stresses in the wake of the crack normal to the fractured surfaces. The load at which the crack closes is therefore tensile rather than zero or compressive. This phenomenon is reffered to ascrack closure. The main objective of this study is to correlate fatigue crack growth rates with crack closure under different types of loadings: Constant-amplitude with two different cycle ratio $\mathrm{R},\left(\mathrm{R}=\boldsymbol{\sigma}_{\mathrm{min}} \text { ! } \sigma_{\max }\right)^{\prime}$, Programmed block loading and A single tensile overload. The incidence of crack closure is examined and the concept of equivalent constant-amplitude is applied. The delayed crack growth retardation after a single overload cycle is interpreted using crack closure concept. Aspects covered include microscopic and fractographic observations confirming the crack closure to provide the fatigue striations on the surfaces ruptured by cyclic loads. Materials used in this study are two Aluminium alloys, widely used in aeronautical structures: $2124 \mathrm{~T} 351$ (AU4GI) and 2618AT85I(AU2GN). Several interaction effects might be explained by changes in the crack closure levels due to variable amplitude loads.

* Lecturer, Dept.of Aeronautical Engineering, Military Technical College, Cairo-Egypt.

** Col.Eng., Head of Planning Dept., Egyptian Airforces Miain Work-

L Shops, Cairo-Egypt. 
FIRST A.S.A.T. CONFERENCE

14-16 May 1985 , CAIRO

INTRODUCTION

Crack closure was first observed by Elber [1] anà has been used to correlate crack growth behaviour under constant-amplitude loadings [2-4]. It is a significant factor in causing load-interaction effects on crack growth rates(retardation and/or acceleration) under variable -amplitude loads. Furnee [5] showed that crack closure should predominately occur near the free surface and to a much lesser extent at the interior of the material. Mc Evily [6] found that peak load introduced a significant crack growth delay. He then reduced the thickness of the specimen immidiately after the peak load and a much smaller delay occured. Elber [7] introducea successfully the equivalent constant-amplitude concept, based on the crack closure phenomena, to replace ranaom load spectra in both analysis and tests. Different techniques are used to measure the crack closure load level, these techniques include: Elber's gauge[1], Schmidt'gauge [8], Photography[9], Laser interferometry[10], Electrical potential [11], Ultra sonic[12] and Photoelasticity[13]. Pelloux [14] measured the crack closure by electrophractography, using high resolution fractography to correlate closure and striation spacings. He pointed out that higher closure developing after overloads was found to be a suitable explaination for crack growth retardation. Bathias [15] showed that the fracture micromorphologie corresponding to the retardation phases are different at mid thickness and near edges of tested specimens; this might suggest a poorer closure at mid-thickness than near edges reflecting smaller delay for thicker specimens. Schijve [16] surveyed the different published formula to determine the crack opening(closure) stress level as a function of cycle stress ratio $\mathrm{R}$. Originally Elber [l] proposed for 2024 T'3 Aluminium alloy tested uncier constant-amplitude loading:

Where

$$
U=\Delta \sigma_{\text {eff }} / \Delta \sigma \quad=\Delta K_{\text {eff }} / \Delta K=0.5+0.4 \mathrm{R}
$$
$\Delta \sigma^{\sigma}=\sigma_{\max }-\sigma_{\min }$ and corresponding $\Delta \mathrm{K}$ is the stress intensity factor range. Consequently $\Delta \mathrm{K}_{\mathrm{eff}}=\mathrm{U} \cdot \Delta \mathrm{K}$ is suggested to replace $\Delta_{K}$ in Paris relation [17]:

$\mathrm{da} / \mathrm{dN}=\mathrm{C}\left(\Delta_{\mathrm{K}}\right)^{\mathrm{m}}$, describing the crack growth rate as function of material's constants $C$ and $\mathrm{m}$; and stress intensity factor range. the complex nature of factors contributing to crack closure makes a pure quantative theoritical study of the phenomenon very diffcult. Therefore crack closure is generally studied experimentally. This research contributes to provide additional phenomenological subjected to:

1. Constant-amplitude loads of two different $\mathrm{R}$ ratio

2. Variable -amplitude loadings in a form of simple flight load simulation(programmed blocks).

3. A single tensile overload cycle introduced during a constant-amplitude sequence.

The developed concepts are based on physical aspects of damage. 


\section{TEST PROGRAM}

The test program was designed so that the crack growth under the two different $R$ ratios $(0.01$ and 0.63$)$ would enable us to determine the crack growth rate curve da/dN $=C(\Delta K)^{m}$ as a single curve independent of the applied load ratio. The simple flight load simulation was designed so that block loads types $\mathrm{C} / \mathrm{n}$ would represent disturbed flights in which the load cycle A $(R=0.01)$ represents the Ground-Air-Ground cycle(G.A.G.) and $n$ load cycles of $B(R=0.63)$ would represent flight disturbing loađ̄s (Gust, Manoeuvre...etc.). n takes values 2,3,6,25 and 69 . The sigle tensile overload test was run for $\tau=2$, where the original constant-amplitude sequence was of $\mathrm{R}=0.01$. In all the three cases, crack closure was monitored and contiuously determined using same technique appliea by Elber [1].

The patterns and loading values for the test program are given in Fig. 1

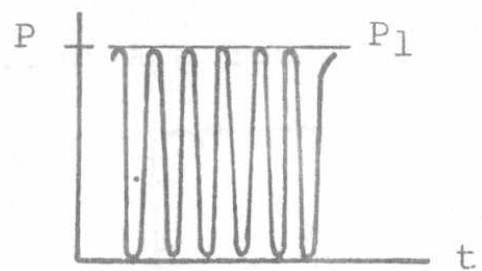

A

P

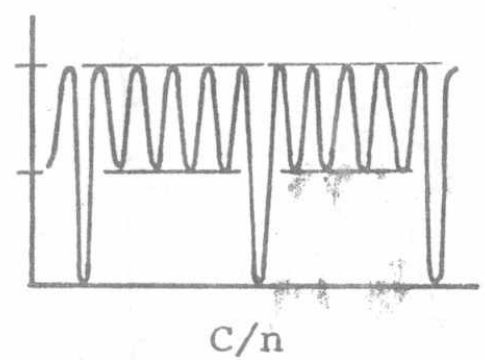

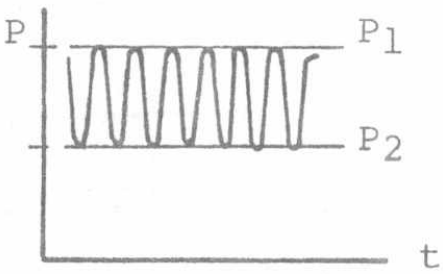

B
Constant-Amplitude

$$
\begin{aligned}
& R_{A}=0.0 I \\
& R_{B}=0.63
\end{aligned}
$$

$\mathrm{P}_{3}$

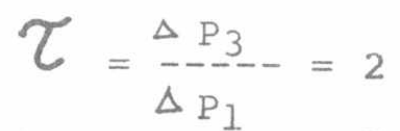

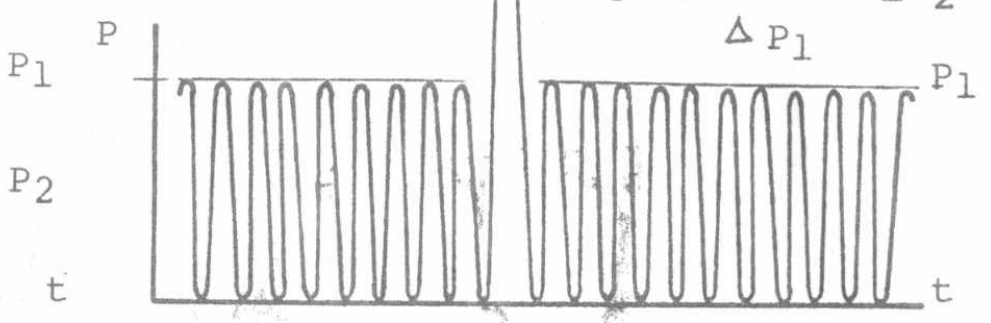

Tensile Overload

Fig. 1 Test Program

\section{Testing Procedure}

Flat, centrally cracked sheet specimens CCT ( $2 \mathrm{~mm}$ thick, $200 \mathrm{~mm}$ wide) and compact tension specimens CT (12 $\mathrm{mm}$ thick,75 $\mathrm{mm}$ wide) were used in this study. Chemical composition, mechanical properties and heat treatment are listed in Ref.[18]. All tests were run at a frequency of $10 \mathrm{~Hz}$ and in air at room temperature. Crack opening level ( $\left.\mathrm{P}_{\mathrm{Op}}\right)$ was measured by a surface gauge located at the crack tip, tests and plots were made at $0.2 \mathrm{~Hz}$ frequency. Tested specimens were examined by scanning electron microscope. 
Test Results and Analysis

Constant-Amplitude

Fatigue crack growth data in the form of da/dN ( $\mathrm{mm} / \mathrm{cycle}$ ) vs stress intensity factor range $\Delta K(\mathrm{MPa} r \mathrm{~m}), \Delta K=C \Delta \sigma \sqrt{\pi \mathrm{a}}), \mathrm{a}$ is crack length in $\mathrm{mm}$, are represented in Fig. 2 . The two alloys showed a significant effect of $\mathrm{R}$ ratio on their fatigue crack growth rates. Higher $\mathrm{R}$ ratio would produce higher propagation rates. Recalling Elber's model:

$$
\begin{gathered}
\mathrm{da} / \mathrm{dN}=\mathrm{C}\left(\Delta \mathrm{K}_{\mathrm{eff}}\right)^{\mathrm{m}} \\
\Delta \mathrm{K}_{\mathrm{eff}}=\mathrm{U} \cdot \Delta \mathrm{K} \quad ; \quad \mathrm{U}=0.5+0.4 \mathrm{R}
\end{gathered}
$$

and based on the data for the $\mathrm{R}$ ratios 0.01 and 0.63 we adopted Elber's single curve independent of $\mathrm{R}$ ratio as shown in Fig. 3 . The two lines of 2818 AT851 are shifted and coincide with Elbers line. Fig.3b shows a typical plot of opening displacement $\delta(\mathrm{mm})$ against the load $\mathrm{P}$ (daN), from which crack opening level ratio: $\alpha=\mathrm{P}_{\mathrm{op}} / \mathrm{P}_{\max }$ for $\mathrm{R}$ ratio 0.1 is 0.5 confirming Elber's model.
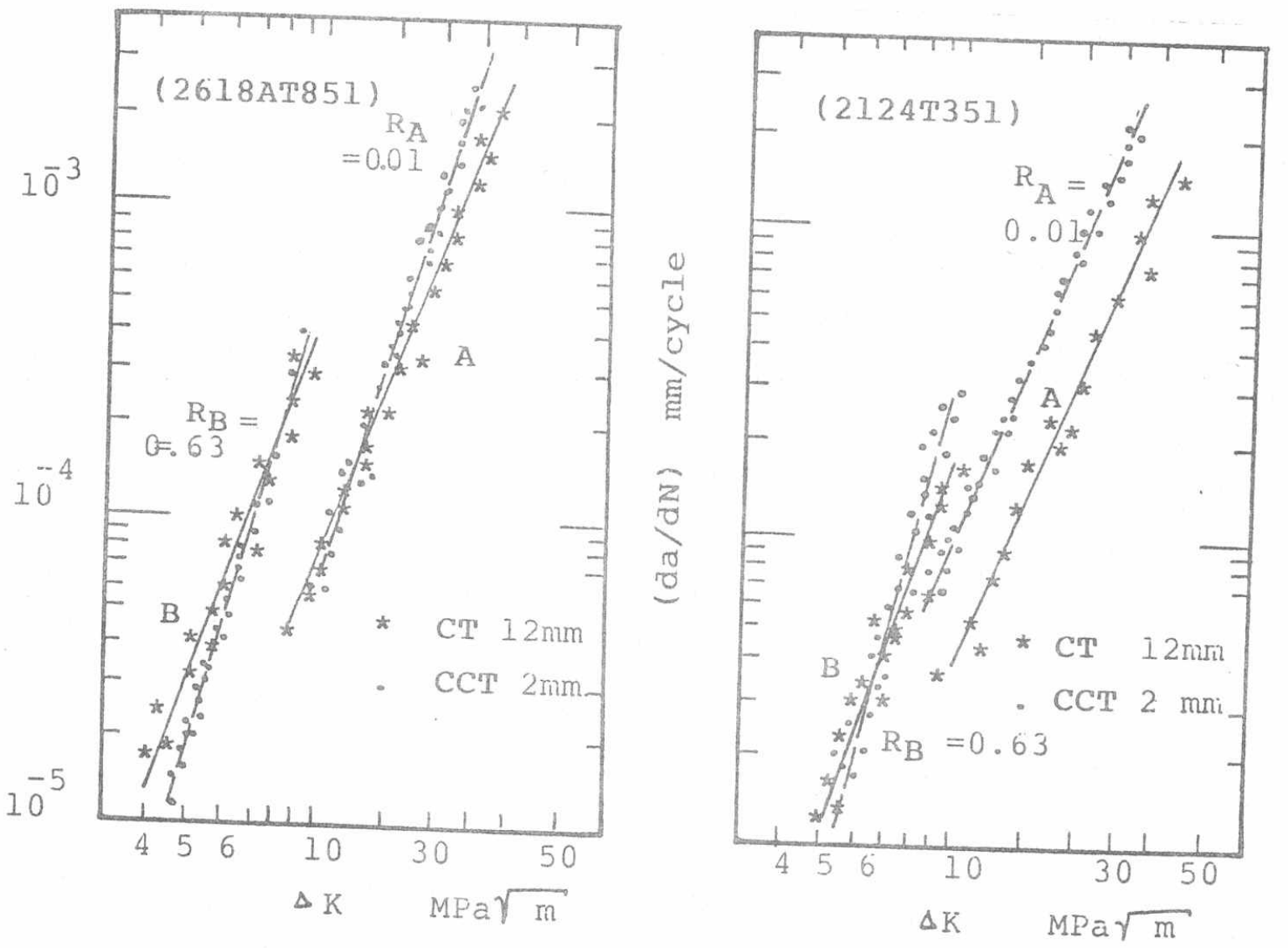

Fig. 2 Crack Growth Rates for $\mathrm{R}=0.1$ and 0.63

Variable-Amplitude

I'ypes $\mathrm{C} / \mathrm{n}$ are characterized by a constant maximum load ( $\mathrm{P}_{I}$ ) and Ly one GAG cycle which occurs once per flight(block). 

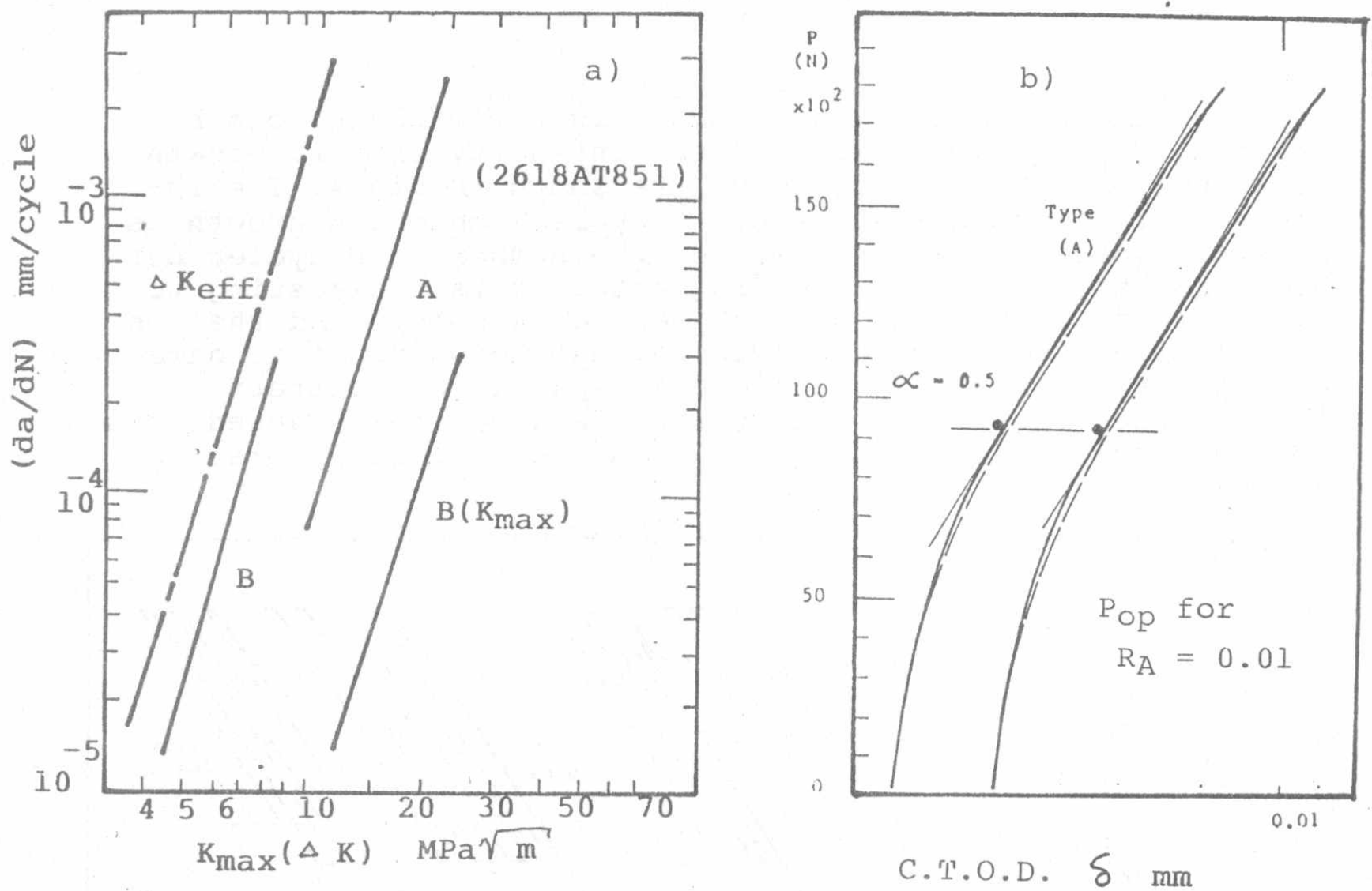

Fig.3 Adoptation of Elber's Line and $\mathrm{P}_{\text {op }}$ for $\mathrm{R}=0.1$

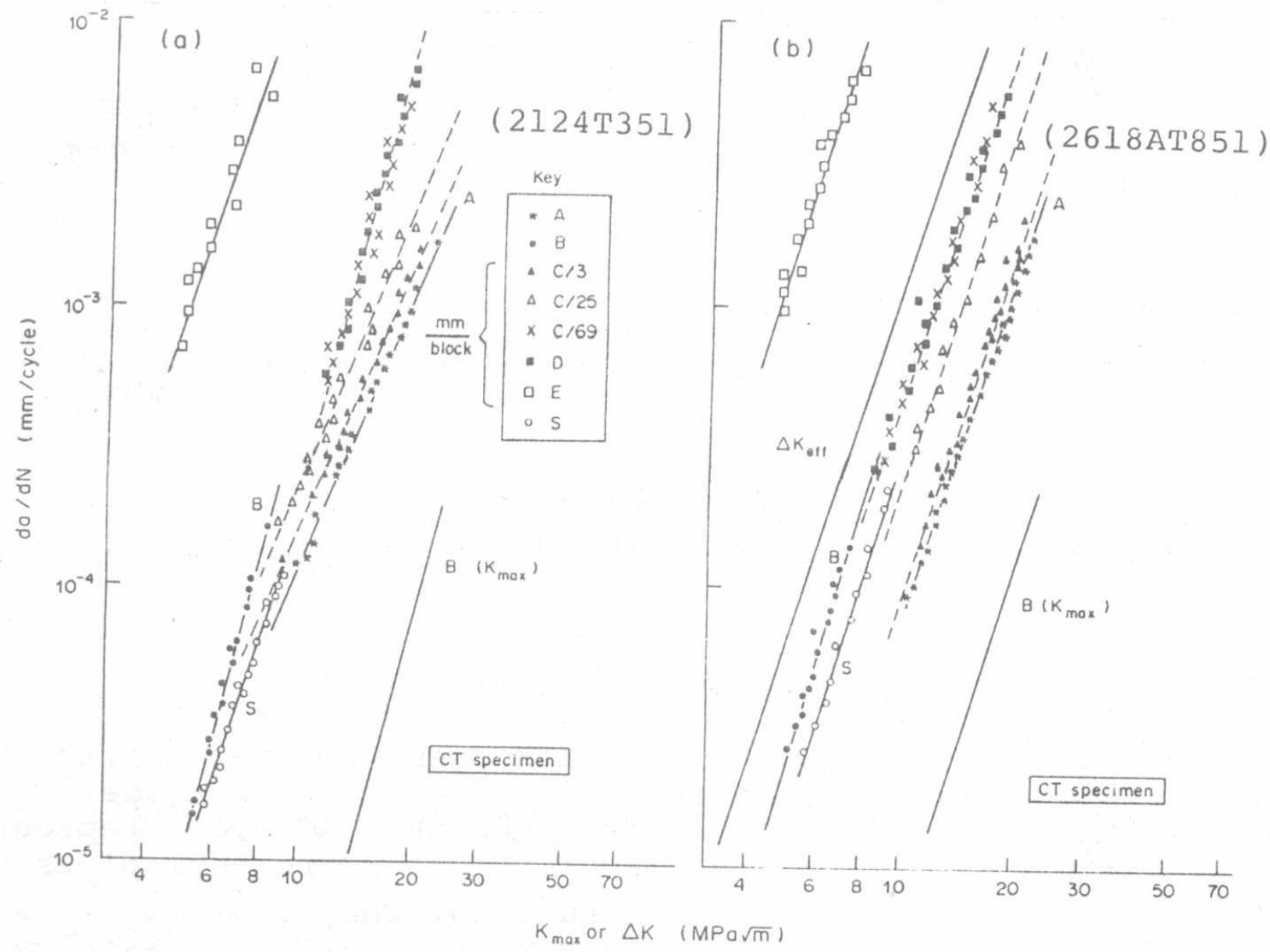

L Fig.4 Crack Growth Rates Under Different Spectra 
Thus, the fatigue crack growth per flight (mm/block) can be plotted vs $K_{\max }$ as maximum stress intensity factor. Growth data for 2618AT851 CT specimens are shown in Fig.4. The influence of flight disturbances (B-cycles) on crack growth is possibly investigated. Increasing the number of B-cycles per block, reflects a higher cracking rate. It is interesting to find a good coincidence between test data points and the noninteraction summation of growth corresponding to basic data of types $A$ and $B$ forming different types of $\mathrm{C} / \mathrm{n}$ pattern. This implies that it is only $R$ ratio effects that caused this growth acceleration without any significant load-interaction effects.

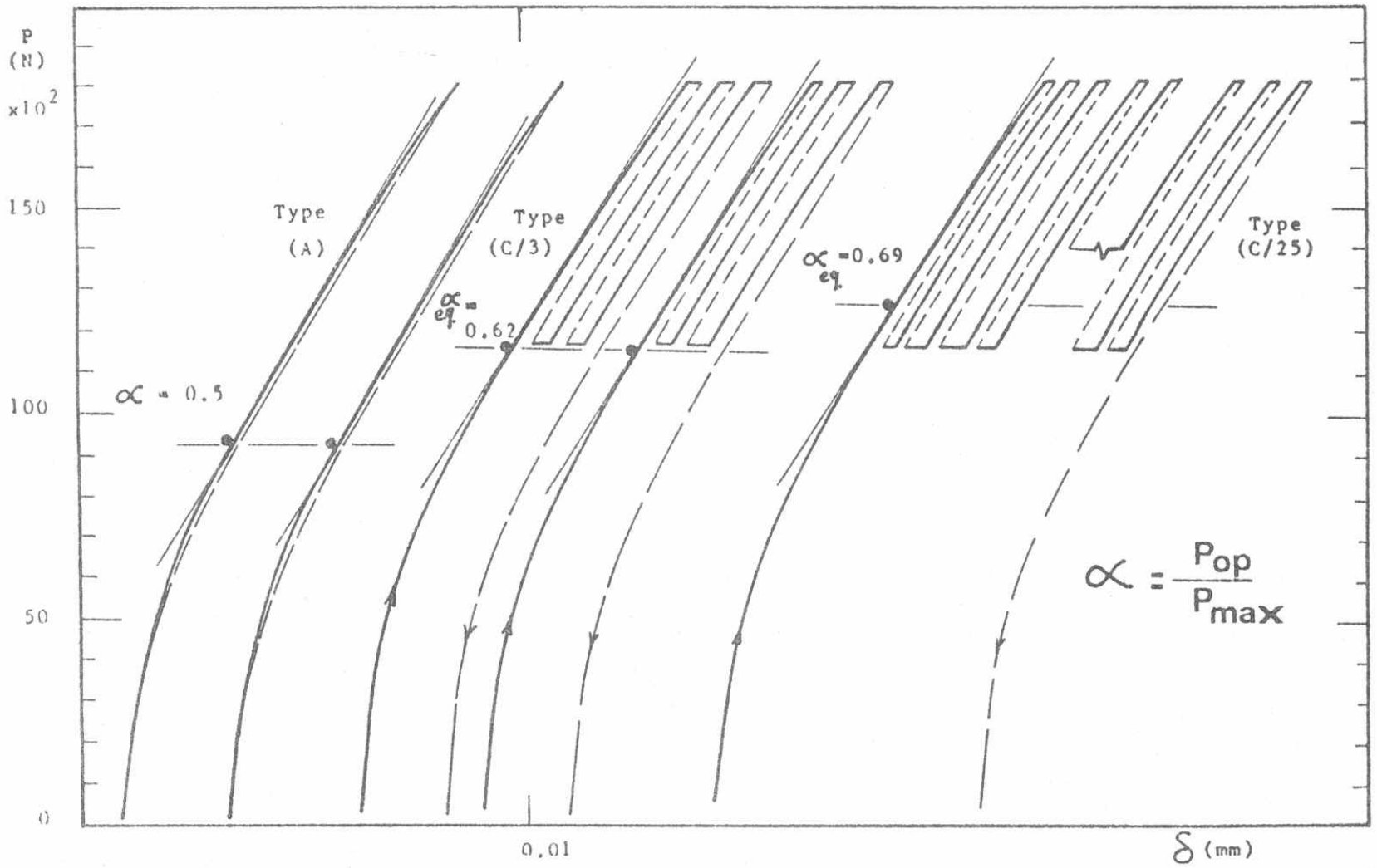

Aluminium Alloy 2124 T $351, C^{r} \mathrm{~B}=2 \mathrm{~mm}$. Fig. 5 .

Determination of $\mathrm{P}_{\mathrm{op}}$ for Block rypes $\mathrm{C} / 3$ and $\mathrm{C} / 25$

\section{Analysis Based on Crack Closure Concept}

It was difficult to measure the crack opening level during the low $\Delta \mathrm{K}$ cycles (B-cycles) in the block $\mathrm{C} / \mathrm{n}$, so we considerea the modification of the opening load $P_{o p}$ on the GAG cycle represent. the equivalent ( $\mathrm{P}_{\mathrm{Op}}$ ).eq. in the block. Fig.5 represents plots of $P=f(\delta)$ for loading types $C / 3$ and $C / 25$. The level of $P_{\text {op }}$ was changed significantly with the number of B-cycles in each type. the avarage values of $\alpha=\mathrm{P}_{\mathrm{op}} / \mathrm{P}_{\max }$ are given in table $\mathrm{l}$. It is logical to expect that for high enough number of B-cycles 
the crack opening level will be stabilizeä and corresponds to $\mathrm{P}_{\mathrm{Op}}$ of the constant-amplitude loading type $\mathrm{B}(\mathrm{R}=0.63)$.

\begin{tabular}{llccc}
\hline Type & A & C/3 & C/25 & B \\
\hline Measured $\alpha$ & 0.5 & $0.61-0.63$ & 0.69 & 0.72 \\
\hline
\end{tabular}

Table 1 Measured Values of Crack Opening Ratio $\propto$ Based on Elber's relation [1]:

$$
\begin{aligned}
& \mathrm{P}_{\max }-\mathrm{P}_{\mathrm{mp}} \quad \mathrm{P}_{\max }-\mathrm{P}_{\mathrm{op}}
\end{aligned}
$$

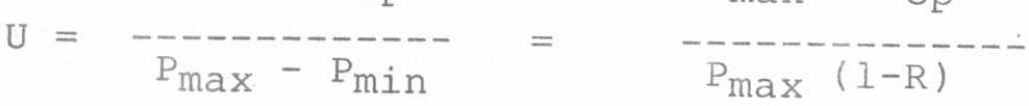

$$
\begin{aligned}
& \mathrm{U}=\quad-\frac{1-\propto}{1-\mathrm{R}} \quad ; \quad \propto \quad=1-\mathrm{U}(1-\mathrm{R})
\end{aligned}
$$

With $\mathrm{U}=0.5+0.4 \mathrm{R}$ for Aluminium alloys

$$
\begin{gathered}
\alpha=0.5+0.1 \mathrm{R}+0.4 \mathrm{R}^{2} \\
\text { So } \alpha_{\mathrm{A}}=0.5 \quad \text { and } \quad \alpha_{\mathrm{B}}=0.722
\end{gathered}
$$

This would suggest that for these types $\mathrm{C} / \mathrm{n}$, will have values such that $\alpha_{A}<\alpha<\alpha_{B}$. We can expect that the crack opening level under such sequences ( $P_{\max }$ is kept constant) is stabilized after some crack growth and remain relatively constant.

Development of Corresponding Equivalent Constant-Amplitude Sequences

Barsom [18] showed that for some random load disturbances, the rate of crack growth was generally equivalent to the rate of crack growth under constant amplitude tests, with the same minimum load and an amplitude representing the root mean square (rms) of the random test. Elber [7] however, introduced this concept based on the crack closure phenomenon and on his test results.

Starting from Elber's definition for constant-amplitude loads and rearranging it as follows:

$$
\begin{aligned}
& \text { da } \\
& -\overline{\mathrm{d}} \overline{\mathrm{N}}-\quad=C_{\text {eff }}\left(\Delta \mathrm{K}_{\text {eff }}\right)^{\mathrm{m}} \\
& =C_{\text {eff }}\left(K_{\max }-K_{o p}\right) \\
& =C_{\text {eff }}\left[K_{\max }\left(1-K_{o p} / K_{\max }\right)\right]^{m} \\
& =C_{\text {eff }}\left[K_{\max }(1-\propto)\right]^{\mathrm{m}} \\
& \text { Assigning } \begin{aligned}
\gamma & =1-\alpha \\
\gamma & =\Delta K_{\text {eff }} / K_{\max }
\end{aligned}
\end{aligned}
$$


Thus $\mathrm{da} / \mathrm{dN}=\mathrm{C}_{\text {eff }}\left(\gamma \mathrm{K}_{\mathrm{max}}\right)^{\mathrm{m}}$

from equation (1) and for Aluminium alloys:

$$
\gamma=0.5-0.1 \mathrm{R}-0.4 \mathrm{R}^{2}
$$

Now several observations can be made:

1. The crack growth rates in $\mathrm{mm} / \mathrm{block}$ for different types $\mathrm{c} / \mathrm{n}$ can be easily determined from the relation da/dN $=f\left(K_{\max }\right)$.

2. Measurements of $\left(P_{o p}\right)$ eq showed that it acquires a certain constant (relatively) value between ( $\mathrm{P}_{\mathrm{Op}}$ ) of type $\mathrm{A}$ and $\left(\mathrm{P}_{\mathrm{Op}}\right)$ of type $\mathrm{B}$ depending on number of $\mathrm{B}$-cycles per block.

3. The greater is $n$, the nearer is $\left(P_{O p}\right)$ eq. to the crack opening level of type $B\left(\mathrm{P}_{\mathrm{OP}}\right)_{\mathrm{B}}$

On the basis of the above considerations, it reasonable to expect that when dividing the growth rates in ( $\mathrm{mm} / \mathrm{block}$ ) by the number of maxima $\mathrm{n}$ per block, we can find equal crack growth in (mm/cycle) based on equivalent damage accumulation due to equal effective stress intensities $\Delta K_{e f f}$ in the block as shown in Fig. 6. Of course this holds good as long as ( $P_{o p}$ ) eq. is higher than $\left(\mathrm{P}_{\min }\right)_{\mathrm{B}}$.

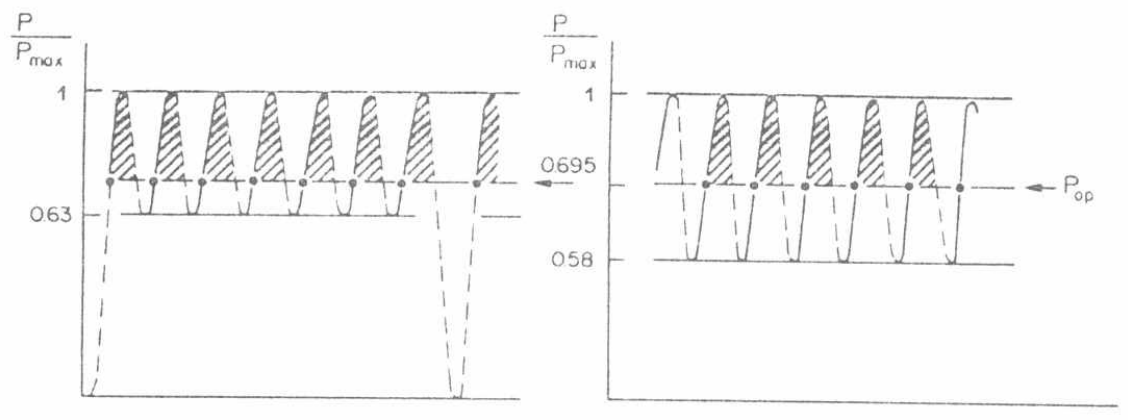

Fig. 6 Interpretation of eq.

We have applied this assessement to find the equivalent Paris relations for each type of $\mathrm{c} / \mathrm{n}$ as indicated in $\mathrm{Fig}$. 7 for the 2618 AT 851 Aluminium alloy.

The principle of equivalent-constant-amplitude loading is to get the same total crack length, an equivalent crack growth mode and an equivalent critical crack length for the two load sequences. All types $\mathrm{C} / \mathrm{n}$ have the same value of $\mathrm{P}_{\max }$ which is kept constant during the block loading. This value of $\mathrm{P}_{\max }$ was taken to be $\mathrm{P}_{\max }$ in the equivalent constant amplitude sequences. Thus, the same plastic zone envelopes are provided as the original block loading. By a simple translation of the equivalent Paris relations given in $\mathrm{mm} / \mathrm{cycle}$ in Fig. 7 to the Elber's line, $\gamma_{\text {eq. corresponding to each }}$ type of $\mathrm{C} / \mathrm{n}$ may be determined. Applying equation (3) corresponding equivalent constant amplitude cycle ratio $\mathrm{R}_{\text {eq }}$ could be determined. rable 2 lists $\gamma_{\text {eq }}$ and $R_{\text {eq }}$ corresponding to each spectrum. Tieste two parameters define the equivalent sequence that would replace the original block loading. A block of $\mathrm{C} / \mathrm{n}$ can now be replaced by $\mathrm{n}$ 
cycles of an equivalent constant amplitude sequence defined by $\mathrm{R}_{\text {eq }}, \mathrm{P}_{\max }$ and $\mathrm{P}_{\text {min }}=\mathrm{R}_{\text {eq }} \times \mathrm{P}_{\max }$.

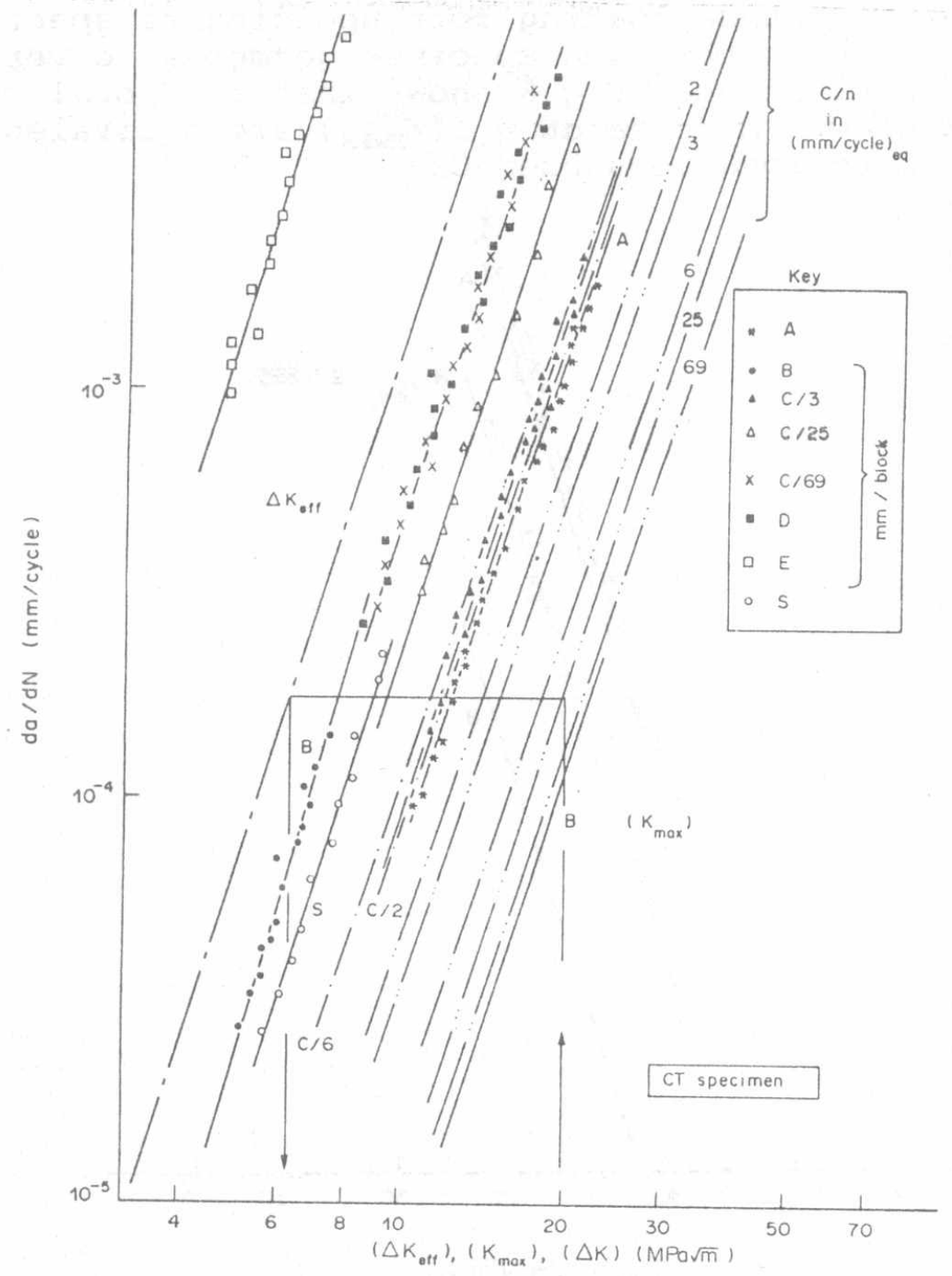

Fig. 7 Analysis Based on Crack Closure Concept

\begin{tabular}{lllll}
\hline Type & $\gamma_{\text {eq }}$ & $R_{\text {eq }}$ & $\alpha_{\text {eq }}$ & $P_{\text {op }}$ \\
\hline$A^{*}$ & 0.5 & 0.01 & 0.5 & $=\left(P_{\text {op }}\right)_{A}$ \\
$C / 2$ & 0.445 & 0.25 & 0.555 & $<\left(P_{\text {min }}\right)_{B}$ \\
$C / 3$ & 0.41 & 0.365 & 0.59 & $\simeq\left(P_{\text {min }}\right)_{B}$ \\
$C / 6$ & 0.355 & 0.489 & 0.645 & $>\left(P_{\text {min }}\right)_{B}$ \\
$C / 25$ & 0.305 & 0.58 & 0.695 & $>\left(P_{\text {min }}\right)_{B}$ \\
$C / 69$ & 0.29 & 0.61 & 0.71 & $>\left(P_{\text {min }}\right)_{B}$ \\
$B^{*}$ & 0.278 & 0.63 & 0.722 & $=\left(P_{\text {op }}\right)_{B}$
\end{tabular}

* Constant amplitudes(originally)

Table 2 Results of Equivalent Constant Amplitude 


$$
\text { MS-6 }
$$

\section{Validity of The Equivalent Constant-Amplitude Concept}

Tests of constant-amplitude loading corresponding to spectra $\mathrm{C} / 3$, $\mathrm{c} / 6$ and $\mathrm{c} / 25$ were run on the same specimen geometry to verify the validity of this equivalence. Fig. 8 shows that the total crack growth and: crack growth mode $d a / d N=f\left(K_{\max }\right)$ are equivalent for the two corresponding load sequences $\mathrm{C} / 3$.

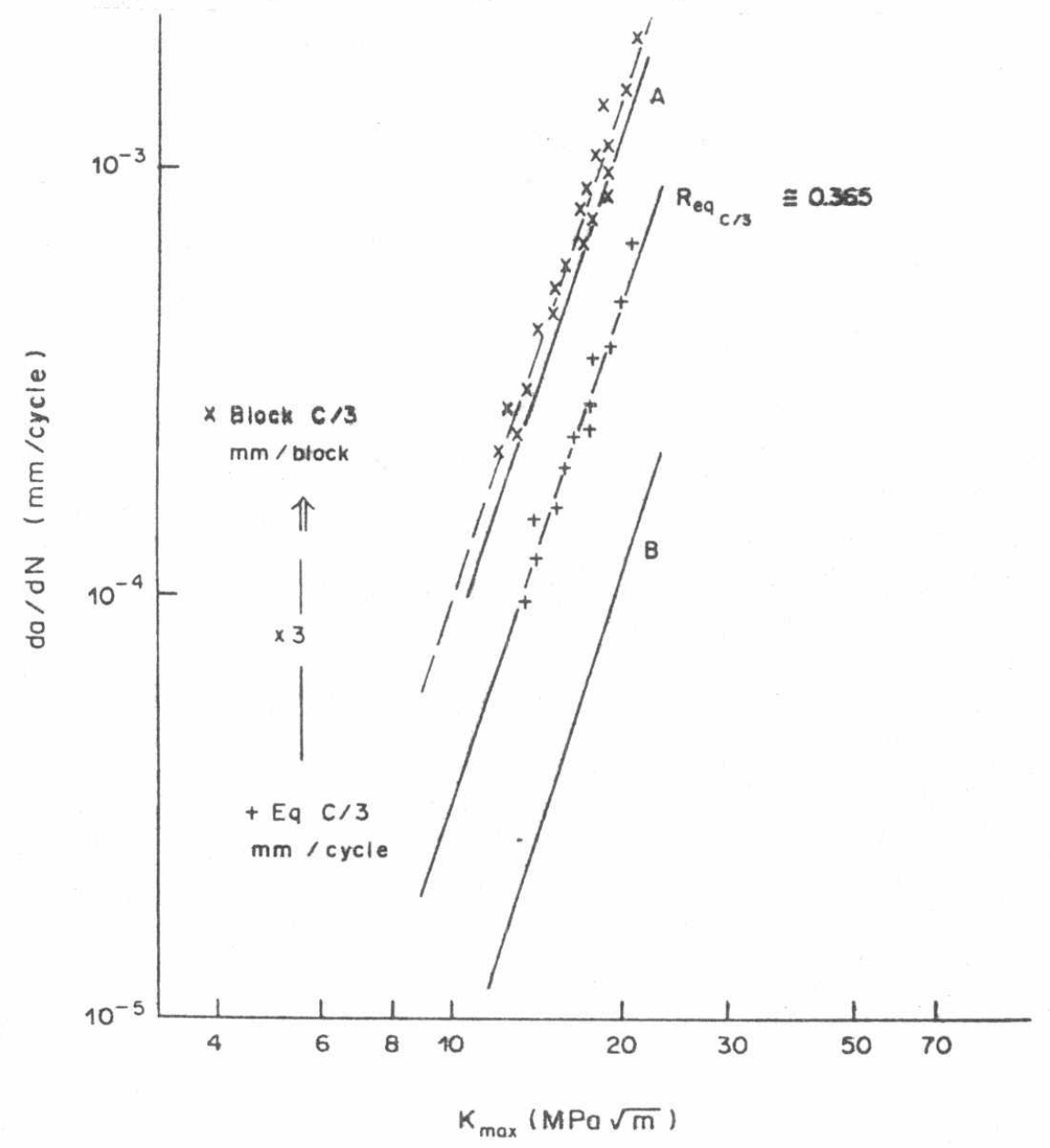

Fig. 8 Validity of the Equivalent Constant-

Amplitude Concept

Table 3 lists the ratio between actual number of blocks and the number of equivalent sequences ( $\mathrm{N}_{\text {ex. }} / \mathrm{N}_{\text {eq. }}$ ). It ranges from 0.88 to 1.02, A range which can be met oftenly in fatigue data and would prove the applicability of this concept.

\begin{tabular}{|c|c|c|c|c|c|c|c|}
\hline Type & $\mathrm{R}_{\text {eq. }}$ & $\begin{array}{l}\mathrm{a}_{0} \\
\mathrm{~mm}\end{array}$ & $\begin{array}{l}a_{f} \\
m m\end{array}$ & $\begin{array}{l}\mathrm{N}_{\mathrm{ex}} \\
\mathrm{block}\end{array}$ & $\begin{array}{l}\mathrm{Neq}_{\text {eq }} \\
\text { cycie }\end{array}$ & $\begin{array}{c}\mathrm{N}_{\mathrm{eq}}(\mathrm{S}) \\
\text { sequence }\end{array}$ & {$\left[-\frac{\mathrm{N}_{\text {ex }}}{\mathrm{N}_{\text {eq }}}-\right]$} \\
\hline$c / 3$ & 0.365 & 26 & 40 & 38100 & 112500 & 37500 & 1.02 \\
\hline$c / 6$ & 0.489 & 26 & 40 & 28000 & 190000 & 31666 & 0.88 \\
\hline$c / 25$ & 0.580 & 26 & 40 & 12700 & 355000 & 14200 & 0.89 \\
\hline
\end{tabular}


Retardation after A Single Tensile Overload

The crack growth data show a strong influence of the parameter $R$, the use of the $\Delta K_{\text {eff }}$ concept based on crack closure data proves to be successful and would suggest that crack closure might be responsible for the $\mathrm{R}$-ratio influence. Attempts have been made to use crack closure in explaining crack growth retardation after overloading $[1,15,20]$. in our present study we measured the change of crack closure after a single tensile overload of $\tau=2$,

$\tau=\Delta K_{\text {ov }} l / \Delta K_{0}$, applied on a CCT 2124 T35l specimen of $2 \mathrm{~mm}$ thickness. Fig.9 shows a typical plot of $\mathrm{P}_{\mathrm{op}}$ level, before, during and after the overload cycle. About 600 cycles after the overload peak were needed so that $\mathrm{P}_{\mathrm{op}}$ would pass again by its original level, about 637.350 cycles were needed so that $\mathrm{P}_{\text {op }}$ level is the highest and about 690.050 cycles so that $\mathrm{P}_{\mathrm{op}}$ regains its original level corresponding to the constant-amplitude sequence.

All documented reports and our experimental results indicate that the retardation after overload is not immidiate. After the overload, the crack can not be closed immidiately upon subsequent cycling, delaying the retardation and possibly causing initial acceleration.
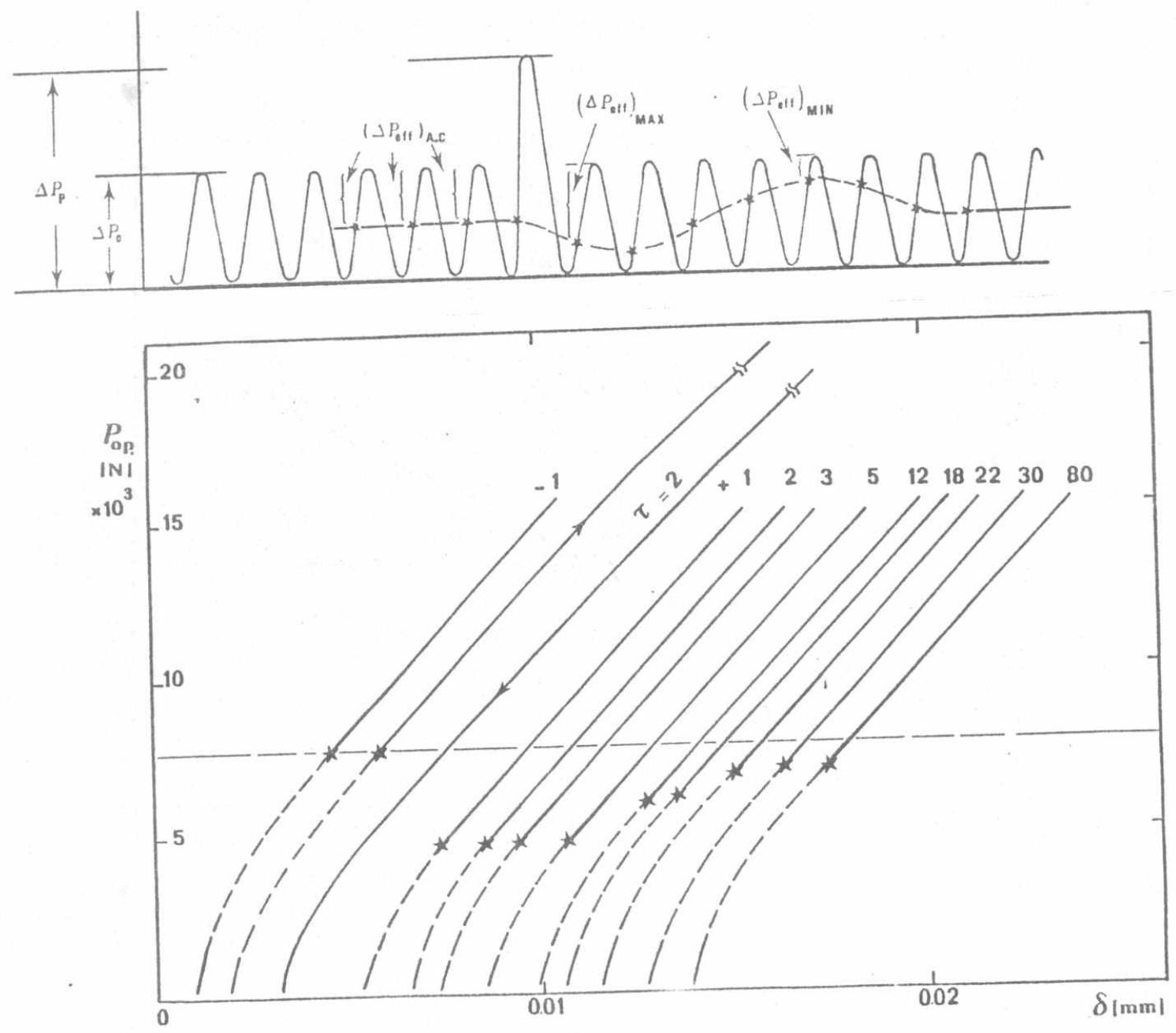

Fig.9 Varaition of Pop Level 


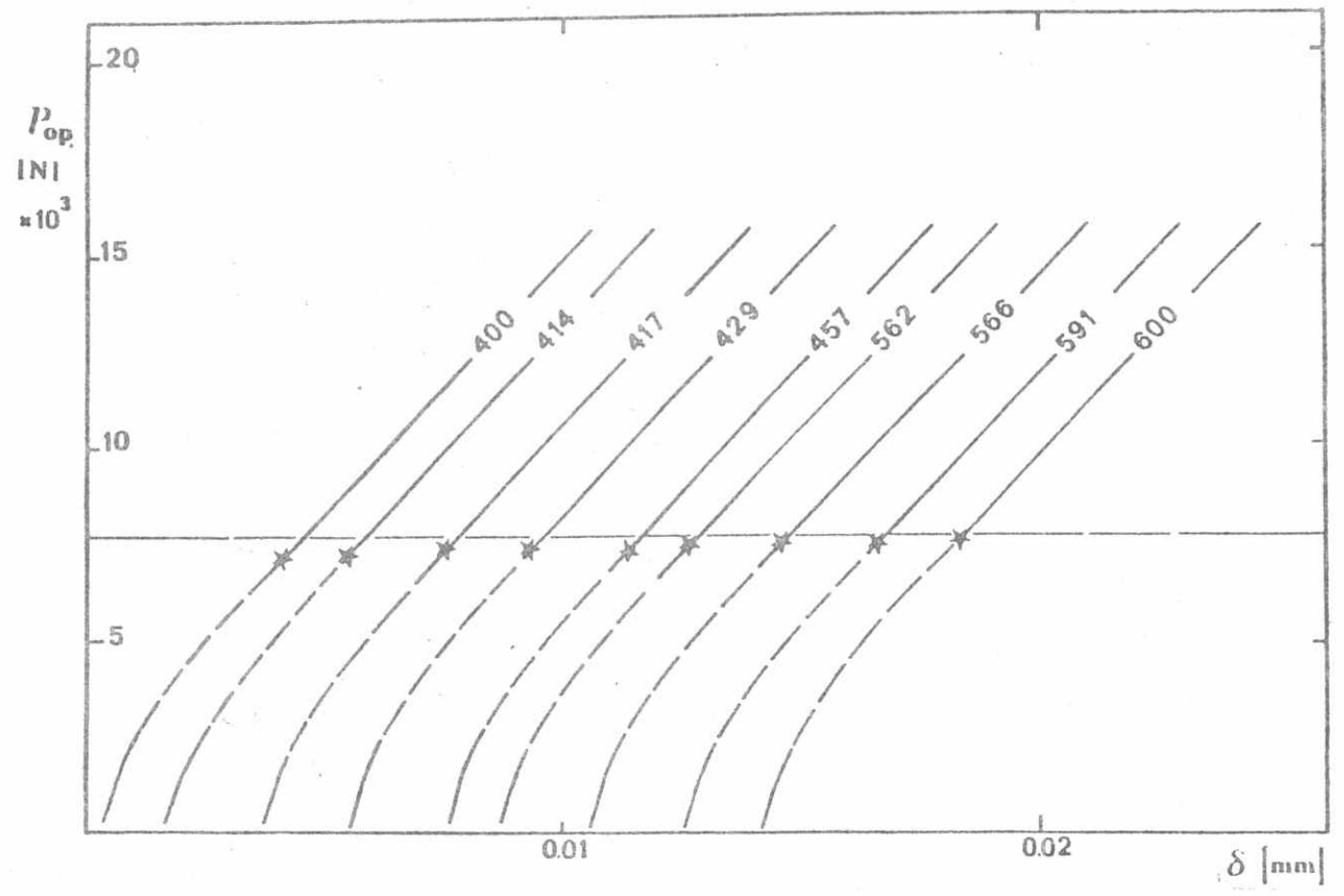

Fig.9 Continue.

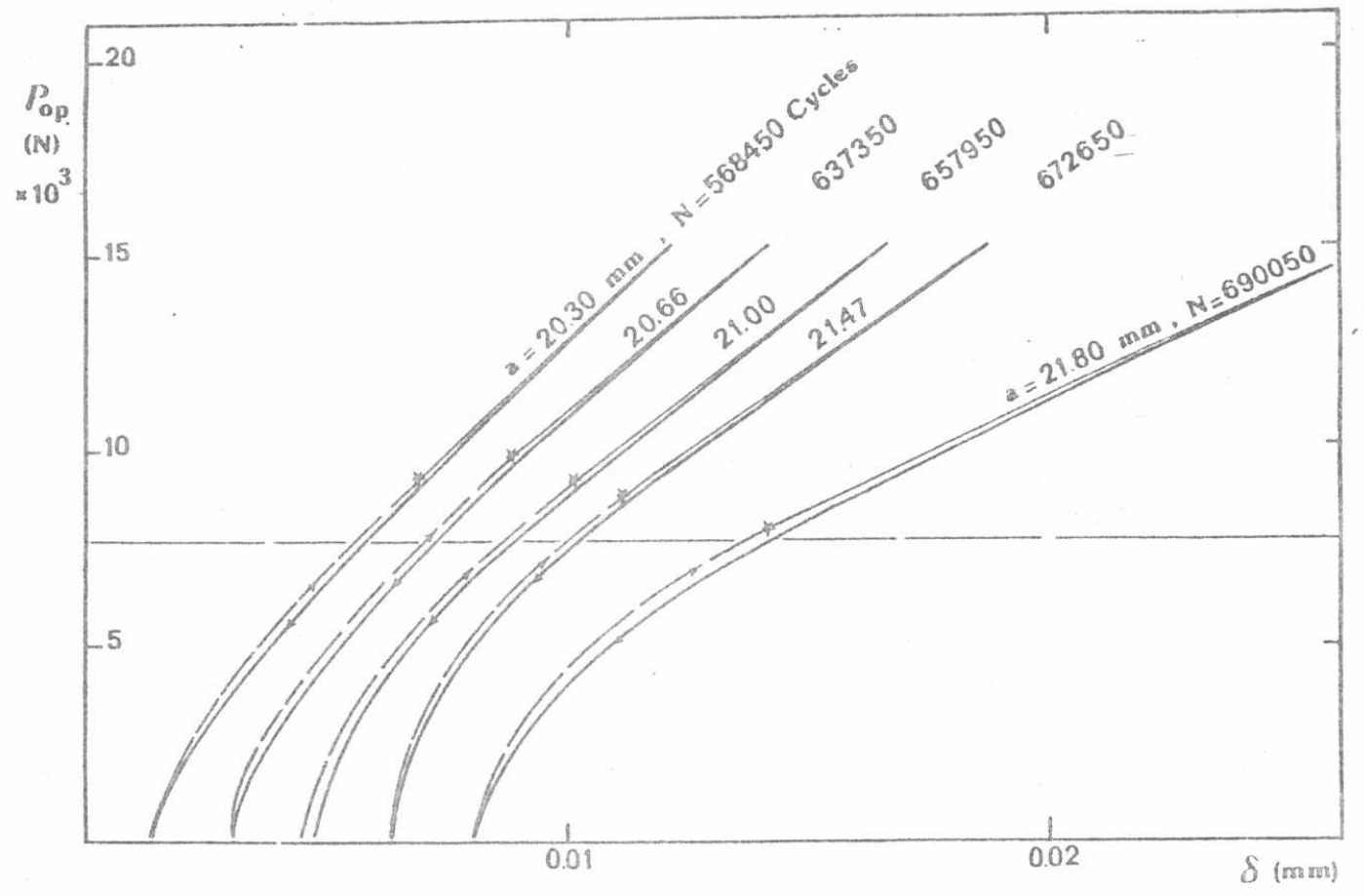

Fig. 9 Continue. 
We think that the 600 cycles after overload peak were consummed in such a delayed retardation. Fig.lo shows that practically crack growth during these cycles was negligible. However, as the crack propagated into the plastic zone, the clamping action of residual stresses acts on the new fracture surfaces. This clamping action builds up reuiring a higher stress to open the crack. As a result the retardation occurs. the crack closure might further explain retardation as follows:

1. Deceleration phase corresponding to the cycles consummed to have maximum opening level(minimum $\Delta \mathrm{K}_{\mathrm{eff}}$ ), 2. A relative acceleration phase corresponding to eycles consummed to regain the original crack opening level. the retardation process is usually described by means of two parameters: $\mathrm{N}_{\mathrm{d}}$, the number of cycles affected by retardation and $\mathrm{a}_{\mathrm{d}}$, the crack length along which the growth rate is disturbed as soon as the overload is applied. Determination of these two parameters based on crack closure concept is illustrated in Fig.10.
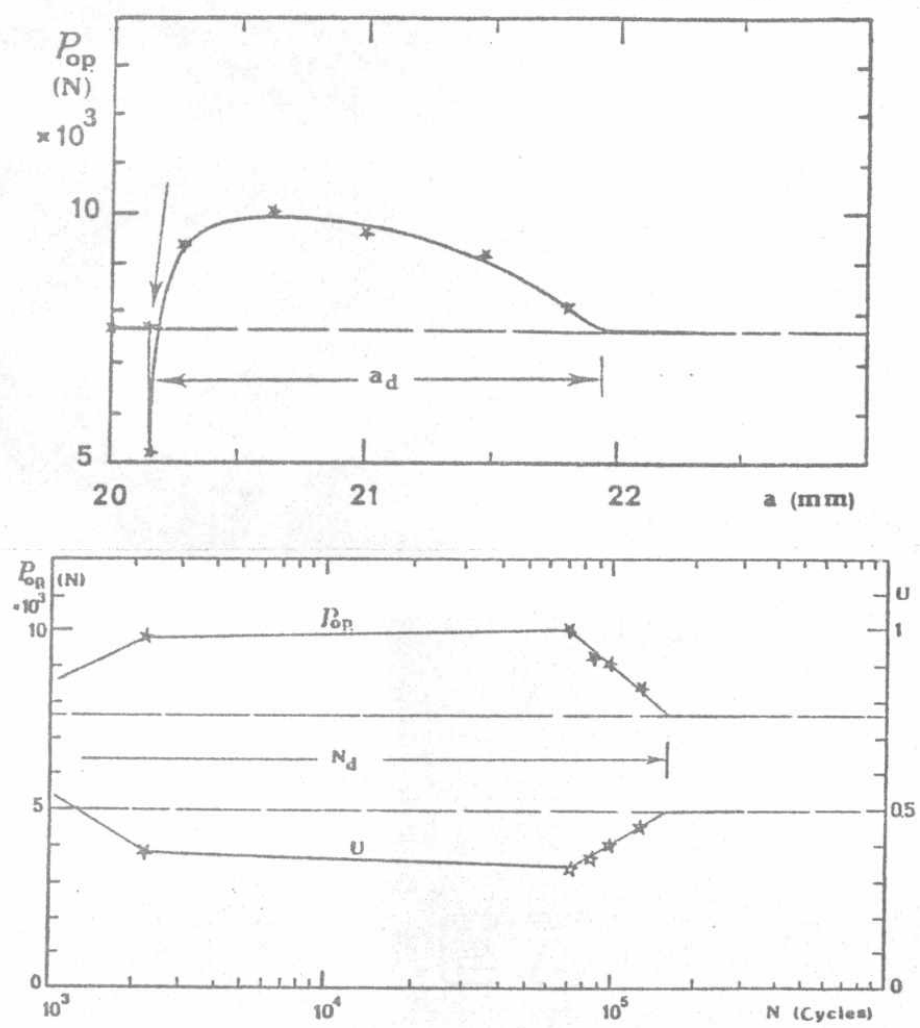

Fig.10 Determination of Retardation Parameters

Several models have been proposed to determine retardation parameters, among which are Wheeler[21] and Willenborg[22]. Unfortunately, the descripencies between experimental and predicted values are large enough. we think that this descripency is due to the fact that both models.are based on immidiate retardation and the relative acceleration phase only, whereas, retardation is not immidiate as discussed before. 
Microfractography

The fractured surface is a finger print or a record of the loads expeienced by the specimens. Cycle by cycle evidence, in the form of striation, of crack behaviour are provided through the use of electron microscope[23]. Tested specimens were examined through the scanning electron microscope. Different aspects of load-time history are easily recognizeà for different spectra.

Different flight types $\mathrm{C} / \mathrm{n}$ and overload retardation are identified in Fig.ll.
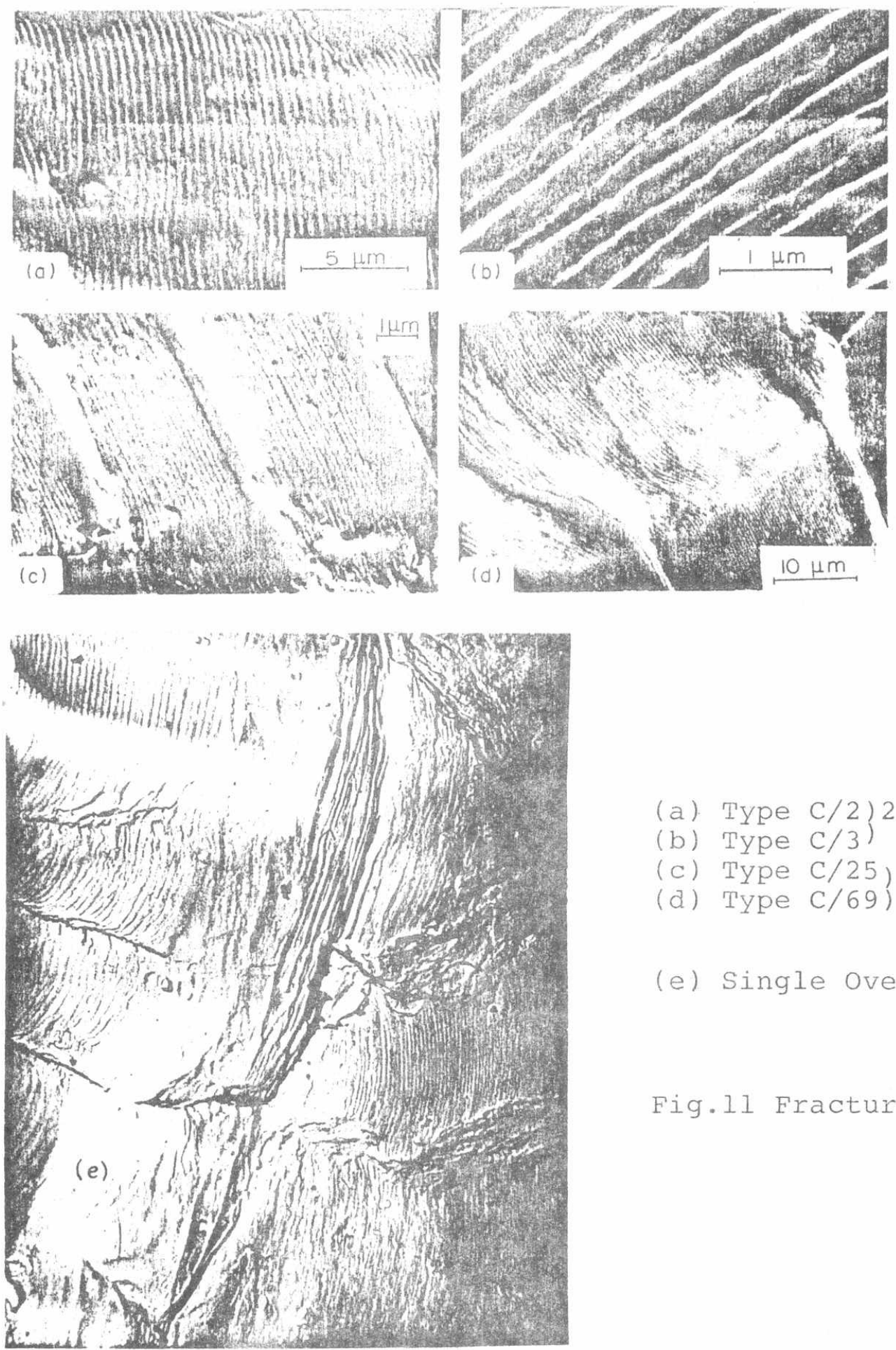

(a) Type $\mathrm{C} / 2) 2618 \mathrm{AT} 851$

(b) Type $\mathrm{C} / 3$ )

(c) Type $\mathrm{c} / 25,2124 \mathrm{~T} 351$

(d) Type $\mathrm{C} / 69$ )

(e) Single Overload

Fig.ll Fracture Surfaces 


\section{CONCLUSIONS}

1. Aluminium alloys respond significantly to variation of the cycle ratio-R.

2. The crack closure gives a significant contribution to the investigation of fatigue crack propagation under variableamplitude loadings.

3. Based on crack closure phenomenon, the developea equivalent constant-amplitude sequences to replace block loads is very promising in fatigue life prediction under variable-amplitude loadings.

4. Crack closure is necessary to define the cycle striation. The significant markings(deep valleys or high peaks) are associated with GAG cycle.

5. Aluminium alloys showed a significant variation in crack closure level after overloads. Crack growth retardation can be attributed to this variation.

6. retardation in Aluminium alloys after single overload is not immidiate, a delayed retardation is noticed. Crack closure concept can successfully account for this phenomenon.

\section{REFERENCES}

[1] Elber,W.,"The significane of fatigue Crack Closure",American Society for testing and Materials,ASTM STP 486,230-242,1971.

[2] Staal,H.U. ana Elen,J.D.,"Crack Closure and influence of cycle Ratio $\mathrm{R}$ on fatigue Crack Growth", Engng.Frac.Mech.,Vol. 11,275283,1979 .

[3] Sunder,R. and dash,P.K.,"Measurement of Fatigue Crack Closure Through Electron Microscopy", Int.J.Fatigue, 97-105,1982.

[4] Schijve,J.,"Four Lectures on Fatigue Crack Growth", Engng.Frac. Mech.,Vol.11,167-221,1979.

[5] Furnee,R.TH.,Thesis, Dept.of Metallurgy, Delft University of Technology (Mar. 1977 ).

[6] MCEvily,A.J.,"Current Aspects of Fatigue"Appendix: Overload Experiments, Fatigue 1977 Conf.University of Cambridge(28-30 March 1977).

[7] Elber,W.,"Equivalent Constant Amplitude Concept for Crack Growth Under Spectrum Loading",ASTM STP 595,236-250,1976.

[8] Schmidt,R.A. and Robert,R., "Observations of Crack Closure", Int.J. Frac. ,8,469-471,1972.

[9] Adams,N.J.,"Fatigue Crack Closure at Positive Stresses",Engng. Fravc.Mech.4,543-554,1972

[10] Sharp,W.N. and Grandt,A.F., "A Preliminary Study of Fatigue Crack Retardation Using Laser Interfrometry to Measure Crack Surface Displacement",AFML-TR-74-203,1975.

[11] Clark,C.K. and Cassat,G.C.,"A Study of Fatigue Crack Closure Using Electric Potential and Complience Techniques"Engng. Frac.Mech, , 9,675-688, 1977 .

[12] Frandsen,J.D. et al, "A Comparison of Acoustic and StrainGauge Techniques for Crack Closure", Int.J. Fract.,11,345348,1975 .

[13] Cheng,Y.F. and Brunner,H.,"Photoelastic Research in Progress on Fatigue Crack Closure", Int.H.Fract.,6,431-434,1970.

[14] Pelloux,R.M. and Faral,M.,"Assessment of Crack Tip Closure in Aluminium Alloy by Electronfractography",Fatigue of Engng. Materials and Structures, Vol. 1,21-35,1979. 
[15] Bathias,C. and Vancon,M.,"Mechanisms of Overload Effect on Fatigue Crack Propagation in Aluminium Alloys",Engng.Fract. Mech., Vol.10,409-424,1978

[16] Schijve,J.,"Some Formulas for The Crack Opening Stress Level", Engng.Fract. Mech., Vol.14,461-465,1981.

[17] Paris, P. and Erdogan, F. , Trans. ASME, J.Basic Engng, 85, 528, 1963.

[18] Gabra,M.,"Fatigue Crack Growth in Aluminium Alloys Under Programmed Block Loading",A.M.E.Conf.,Military Tech.College, Cairo, 55-65, 1984 .

[19] Barsom, J.M.,"Progress in Flaw Growth and Fracture Toughness Testing,ASTM STP 536;147-167,1973.

[20] Chanani,G.R. and Mays, B.J. Engng.Fract.Mech. , 8, 507, 1976.

[21] Wheeler,O.E.,"Spectrum Loading and Crack Growth",J.of Basic Engrig. Trans. ASME, 181-186,1972.

[22] Willenborg,J.C. et al,"A Crack Growth Retardation Model using an Effective Stress Concept",AFFDL-TM-FBR,71-1, AIRFORCE FLIGHT DYn。-Lab.,1971.

[23] Abelkis,P.R.,"IIse of Microfractography in The Study of Fatigue Crack Propagatıon Under Spectrum Loading, ASTM STP 645,213-234 1978 . 